\title{
The Cross-Boundary Integration Development of Internet+ Sports Industry
}

\author{
Xianghui Cong, Huaijin Liu \\ Country Faculty of P.E., Hunan Institute of Science and Technology, Yueyang, China \\ Email: tyxlhj@126.com
}

How to cite this paper: Cong, X.H. and Liu, H.J. (2019) The Cross-Boundary Integration Development of Internet+ Sports Industry. Open Journal of Social Sciences, 7, 52-60.

https://doi.org/10.4236/jss.2019.710005

Received: June 11, 2019

Accepted: October 9, 2019

Published: October 12, 2019

Copyright $\odot 2019$ by author(s) and Scientific Research Publishing Inc. This work is licensed under the Creative Commons Attribution International License (CC BY 4.0).

http://creativecommons.org/licenses/by/4.0/

\begin{abstract}
Internet+ sports industry cross-boundary integration is an important way to accelerate the development of sports industry and promote sports consumption. At present, the development mode, ecosystem and development elements of traditional sports industry are important factors that restrict the cross-border integration of the Internet+ sports industry. It is necessary to seek the cross-border integration development path of the Internet+ sports industry by formulating the integrated development plan, strengthening the construction of talent team and innovating industrial brand resources.
\end{abstract}

\section{Keywords}

Internet+, Sports Industry, Cross-Boundary Integration

\section{Introduction}

In recent years, the sports industry has shown a good development trend. From the national level, the State Council's Opinions on Speeding up the Development of Sports Industry and Promoting Sports Consumption in 2014 emphasized "Promoting Fusion Development" [1], stimulated the market vitality of sports industry, provided endogenous power and policy support for the cross-border integration of sports industry and Internet. In 2016, the 13th Five-Year Plan for the Development of Sports Industry of the General Administration of Sports put forward "Active Promotion". "Internet+ sports" encourages the development of sports services supported by mobile Internet technology [2]. It can be seen that both the state and the industry attach great importance to the development of sports industry and its integration with related industries. But how to integrate the sports industry with the Internet+ development has not attracted enough attention from the state and the industry. This article will start with the connotation of the Internet+ sports industry, and further explore the cross-border inte- 
gration background and innovation formats, integration demands and development path of the Internet and sports industry, better promoting the Internet+ sports industry good and fast cross-border integration and development to provide academic basis and decision-making support. Sports industry is a comprehensive industry, including sports products manufacturing industry, sports venues service industry, sports performance industry, sports fitness and entertainment industry, sports tourism and sports gambling industry and many other aspects. At present, the penetration of Internet technology into the sports industry and the use of the Internet platform by the sports industry have jointly promoted the formation of a new pattern of the current sports industry. The Internet+ sports industry is based on the Internet as the platform and tools, aiming at improving the production efficiency and quality of sports products, and promoting the development and innovation of sports industry through the cross-boundary integration of the Internet and sports industry.

\section{Cross-Boundary Integration Background and Innovative Formats of Internet+ Sports Industry}

The cross-boundary integration of the Internet+ sports industry is not only the internal driving force of the sports industry policy encouragement, but also the result of the external power engine driven by the Internet technology in the Internet+ era. Clarifying the integration background of the Internet+ sports industry will help promote industrial innovation, transformation and upgrading of sports products, structure, function, service and value, and promote the formation of the new format of the Internet+ sports industry.

\subsection{Cross-Boundary Integration of the Internet+ Sports Industry}

Cross-border integration refers to cross-industry and cross-field cooperation, also known as cross-border collaboration. Cross-border integration can lead to unrelated industrial cooperation, new formats and new values. In recent years, the implementation of the "Internet plus" action plan has effectively promoted the organic integration of the Internet and all walks of life, and the Internet+ sports industry has also emerged as the times require. Now it has become the focus of attention in the sports market. Especially, the application of cloud storage, data retrieval, collection, processing and transmission technology based on the Internet in sports industry has greatly promoted the extensive penetration and effective extension of Internet thinking in sports industry and has become an important engine and driving force for the development of the deep integration of sports industry and Internet. A new ecological system of sports industry has been formed through cross-border integration. We will accelerate the transformation and upgrading of the sports industry.

\subsection{Cross-Boundary Integration of Internet+ Sports Industry}

Business form refers to the form of industrial research and development, pro- 
duction and sales, also known as industrial form. The integration of different industries can produce a new industry form different from the traditional industry, that is, industry innovation. The development of traditional sports industry has formed the traditional form of sports industry. With the development of science and technology and social progress, the traditional sports industry can no longer meet the growing sports demand of the people. It must develop new sports industry. The integration of the Internet and sports industry is an important means to develop new sports industry, and it will become the inevitable trend of the development of sports industry. Sports products manufacturing industry, stadium service industry, sports competitive performance industry, sports fitness and entertainment industry, sports tourism industry and sports gambling industry need to rely on the Internet platform, use new network media and intelligent equipment to innovate and upgrade the industry, and promote the use of large data and mobile Internet for information storage, transmission and interaction of intelligent stadiums and gymnasiums.

By integrating and classifying the information of gymnasiums, we can realize the intelligent management of gymnasiums and gymnasiums, accurately and efficiently provide information such as consumption price, opening time, site resources, etc. Mobile fitness APP can accurately record the quantity indexes of exercise time, exercise load and heat energy consumption of sports crowd, and provide objective basis for scientific formulation of fitness exercise prescriptions; Sports goods network sales break through traditional channels. Limitations such as smoothness and inadequate competitiveness provide network platform to build an interactive platform for sales and consumption, change the sales model and marketing concept to better meet the needs of sports crowd; intelligent sports equipment and wearable equipment facilitate sports crowd to timely monitor their own sports status data and reasonably formulate sports programs; Tencent, Sohu, Sina and other social media rely on the Internet to establish many projects. The diversified and functional portal website enables sports enthusiasts to enjoy live or broadcast sports events online without leaving home and across time and space, so as to enhance the operational capacity of the sports performance industry.

The integration of Internet and sports industry will reconstruct the form of sports industry, which will influence the sports ecology with new concepts and technologies. The sports industry practitioners can not only inject technological innovation elements into sports industry research and development, but also promote sports brand building concept, sports product sales channels, sports consumption service mode innovation, and promote sports products, structure, function, service and value.

\section{Internet+ Sports Industry Cross-Border Integration Appeal}

\subsection{Abbreviations and Acronyms}

Define abbreviations and acronyms the first time they are used in the text, even 
after they have been defined in the abstract. Abbreviations such as IEEE, SI, MKS, CGS, sc, dc, and rms do not have to be defined. Do not use abbreviations in the title or heads unless they are unavoidable.

\subsection{The Development Model of Traditional Sports Industry Needs to Be Innovated Urgently}

For a long time, the traditional sports industry has formed its fixed technology mode, production mode and marketing mode [3]. in the era of "Internet + ", new ideas and ideas have posed new challenges to the traditional sports industry mode. First, the technological model of sports industry needs to be digitized urgently. With the help of network platform, more and more sports people can watch sports programs online anytime and anywhere, search sports resources on the Internet, and carry out sport's social activities. Traditional sports industry needs to complete the digital transformation in time to survive and develop better. Second, the production mode of sports industry urgently needs intellectualization. In the Internet era, the consumption intention, habits and tendencies of sports consumers depend more and more on Internet platform, Internet community and e-commerce platform, which directly affects the production and service supply of sports products. Intelligent running shoes, intelligent bicycles and intelligent training equipment are constantly emerging. Intelligent sports products call for intelligent production mode and service customization. Third, sports industry marketing model needs to be shared urgently. Internet interconnection and clustering characteristics shape social groups with the same interests and interests. Different sports projects and sports products connect the corresponding sports groups. Sports resources and information are shared within the groups. The original competition-oriented marketing model no longer adapts to the business environment of the Internet era. Sports industry needs to form a camp of sharing resources and information. Therefore, in the era of "Internet+", the sports industry can only change its technological mode, production mode and marketing mode in a timely manner, so that it can follow the trend and seek greater development space with the pace of "Internet+".

\subsection{The Ecosystem of Traditional Sports Industry Needs to Be Reconstructed Urgently}

The traditional sports industry ecology includes the industrial main body, the production process and the business mode [4]. In the era of "Internet+", the atmosphere of cooperation, sharing, cooperation and opening brings opportunities to the traditional sports industry ecology. Firstly, the main structure of sports industry urgently needs to be diversified. The main body of traditional sports industry mainly includes government departments, production enterprises and consumer groups. The government leads the development of industry. Enterprises are responsible for the production and sale of sports products, and individuals consume sports products in a limited way. In the era of "Inter- 
net+", all Internet gangs enter the sports industry through financing and investment, sports products sales and consumption channels are networked, sports industry ecology is increasingly diversified, and the main structure of the industry needs to be adjusted in time. Second, the production process of sports industry needs to be customized urgently. The production process of traditional sports industry includes design, production, packaging and factory leaving. Each link runs in series and closed-loop. In the Internet era, strong technological innovation forces have subverted the traditional sports industry process. Under the support of the network platform, sports consumption has changed from passive acceptance to active participation. Pre-consumption affects the decision-making, design, sales and service of sports products, showing a personalized and customized trend. It is imperative to customize production process. Thirdly, the marketing channels of sports industry need to be networked urgently. Traditional sports industry sales channel is "sports enterprise production + channel marketing distribution" line, sports products only after the sale of cost recovery and income. In the Internet era, from sports products to competitive performance industry, there are flexible and decentralized consumer groups. The sales channel has also changed from the traditional "cost-benefit" single path to the network-related channel in the network era. Only when the sports industry sales channel is networked can it obtain greater benefits. Therefore, in the era of "Internet+", the sports industry ecology needs to be rebuilt in line with the characteristics of the network society. According to the network order, we should adjust the industrial main body, the production process and the sales channels, and seek greater opportunities for development in the network time and space.

\subsection{The Development Factors of Traditional Sports Industry Need to Be Improved Urgently}

The traditional sports industry has formed a relatively conservative development direction, development power and development platform. In the era of "Internet plus", characteristics such as anytime, anywhere, sharing and interconnection have provided favourable conditions for the innovation and development of traditional sports industry. Firstly, the development direction of sports industry needs to be adjusted urgently. The development direction of traditional sports industry is relatively single, industrial technology is relatively backward, industrial structure is relatively solidified, long-term stability in a certain economic and social basis, to provide solidified sports products and services for sports consumers [5]. In the era of "Internet plus", sports industry needs cross-border integration, technological innovation and optimization structure, and then adjusts the direction to enhance industrial ecology and promote the sustainable development of sports industry. Secondly, the motive force of sports industry development needs to be strengthened urgently. The implementation of the "Internet plus" action plan has brought new impetus to all walks of life. As 
far as sports industry is concerned, the important factor of its transformation and upgrading is that the state pays attention to the policy motive power of the top-level design for the development of the Internet industry, the ideological power of the masses to actively welcome the Internet+ sports industry, and the technological power of Internet sensing and Internet of things technology applied to the sports industry. Only by making full use of policy, thought and technology and grasping the direction of development, can the sports industry adapt to the trend of the times and develop rapidly. Thirdly, the development platform of sports industry needs to be built urgently. The Internet has not only transformed the sports industry, but also set up a platform for the optimization and development of the sports industry. Wired wireless network provides a broad space and time for the transformation and development of sports industry. Interconnection provides unlimited possibilities for the transformation and development of sports industry. Sports industry needs to be fully developed.

\section{Internet+ Sports Industry Cross-Border Integration Development Path}

The 13th Five-Year Plan for the Development of Sports Industry of the State General Administration of Sports in 2016 calls for taking innovation as a powerful driving force to promote sports development, fully stimulating the innovative vitality of various subjects, actively promoting theoretical innovation, institutional innovation, scientific and technological innovation and cultural innovation, promoting mass entrepreneurship and innovation among all people in the field of sports, and exploring a new mode of sports development [2]. The sports industry should seek the cross-border integration and development path of the Internet+ sports industry by formulating the integrated development plan, strengthening the construction of talent team and innovating the brand resources of the industry.

\subsection{Formulating an Integrated Development Plan}

At present, our country is undergoing the transformation of market economy, and sports industry resources are mostly in the hands of the government [6]. The cross-boundary integration development plan of the Internet+ sports industry is playing an active role in the process of industrial integration. Therefore, the government departments should formulate the cross-boundary integration development plan of the Internet plus sports industry scientifically, determine the direction of development, condense the driving force for development, set up a development platform, and provide an action guide for the cross-boundary integration of the Internet+ sports industry. The cross-boundary integration of the Internet and sports industry requires the government to do top-level design, take the overall situation into consideration, determine the development direction of networking, socialization and marketization of sports industry, implement the plan of "Internet plus", consolidate the driving force of 
the intense competition of sports enterprises, the driving force of diversification of sports market demand and the driving force of sports related industrial policies [7]. Based on the Internet to build a platform for the development of sports industry, to achieve the customization of sports products P2P [8] (Peer to Peer, end-to-end), to enhance the connotation of sports products manufacturing industry, to meet the individual experience of sports crowd, to promote $\mathrm{O}_{2} \mathrm{O}$ [9] [10] (Online to Offline, online and offline) services, enhance user stickiness and use loyalty, improve the quality of sports products and service efficiency, guide and support the development of Internet+ sports industry, encourage the development of mobile Internet based sports cloud platform and sports e-commerce platform [2], so that "Internet+" can be achieved online in sports industry. The combination of offline, traditional and modern will promote cross-border integration and sustainable development of sports industry.

\subsection{Strengthening the Construction of Talented Personnel}

The composition of sports talents affects the development of sports industry. Sports enterprises should strengthen the construction of talent team by means of open recruitment and regular training, and create a good environment for sports industry software and hardware by innovating technological mode, optimizing production mode and reconstructing marketing mode. Under the background of "Internet+", many non-sports professionals with computer network software and hardware knowledge have crossed the boundary into the sports industry, promoting the integration of knowledge and promoting the concept innovation. Encourage technology integration and innovation through talent integration, and actively develop new business on the basis of innovative technology, so as to achieve business integration [11]. We should keep abreast of the trend of the times, form a service flow of "user + data + service + terminal" and innovate technological model with big data. Based on data mining technology, this paper analyses the consumption intention, habits and direction of sports consumers, realizes precise customization of sports products and precise supply of sports services, so as to reduce production costs, improve the utilization rate of raw materials and optimize production mode. With the help of the Internet, sports product marketing, sports e-commerce, sports production enterprises to build sales websites, etc., through the "online platform" and "off-line resources", optimize marketing methods and service quality. At the same time, it calls on government departments to formulate effective policies suitable for the development of sports industry in the Internet era, and to promote the development of sports industry operation mode [12]. Sports enterprises should constantly reflect and summarize, draw lessons from failure, and constantly optimize and reconstruct the marketing model of sports industry.

\subsection{Brand Resources of Innovative Industries}

Traditional industries have their own products and resources, seek survival and 
development in the competition among peers, and have formed their own brand. Competition is the driving force of development. In the Internet era, the channels and ways of competition are more diversified and intensified. Sports industry needs to implement the main body of industry, reconstruct production process, rebuild industrial ecology, innovate product brand resources, and constantly enhance comprehensive strength and competitiveness in order to survive and develop better. At the same time, "Internet+" should promote the change of the main body of the sports industry. We can realize the government's emphasis on the Internet+ sports industry through the recognition of the Internet value of the industrial entities, promote the understanding of the "Internet+ traditional sports industry" by the enterprises, promote the allocation of resources and the industrial policies of the sports industry, and better serve the sports industry consumer groups. Data mining and cloud computing prediction based on the Internet will integrate the consumer's pre-consumption behavior into the decision-making, design, production and sales of sports products, improve the individualization and customization of sports products and services, and reconstruct the production process. The government departments should make overall planning and do top-level design. Enterprises should share resources and enhance efficiency. Through the Internet+ sports industry cross-boundary integration, we can integrate online and offline, traditional and modern, and form an inter sectoral, cross industry and cross temporal industrial ecology [4].

\section{Acknowledgements}

This study was sponsored by the scientific research project of General Project of Hunan Philosophy and Social Science Foundation Program "Research on Co-construction and Sharing Model and Mechanism Innovation of Digital Teaching Resources of Physical Education Courses in Universities and Colleges under the Background of MOOC" (16YBA181), Provincial Social Sciences Achievement Review Committee "Research on the Construction Path and Mechanism Innovation of College Physical Education Course Network Teaching Resources Based on Cloud Computing" (XSP18YBC141), Research project on teaching reform of universities in Hunan province "Construction and practice of the resource-sharing model of high-quality online physical education courses in colleges and universities based on O2O" (xiangjiaotong[2019]no. 291:617), Hunan Provincial Education Department "Research on the Improvement of College Physical Education Teachers' Informatization Teaching Ability under TPCK Framework" (18C0629) and the research project of Hunan Institute of Technology in teaching reform "Physical Education On-line and Off-line Course Construction and Promotion Applied Research” (No. 47, 2018).

\section{Conflicts of Interest}

The authors declare no conflicts of interest regarding the publication of this paper. 


\section{References}

[1] State Council (2014) Several Opinions on Accelerating the Development of Sports Industry and Promoting Sports Consumption. http://www.gov.cn/zhengce/content/2014-10/20/content_9152.htm

[2] General Administration of Sports of China. Thirteenth Five-Year Plan for Sports Industry Development. http://www.sport.gov.cn/n10503/c722960/content.html

[3] Xia, Y.Q. (2016) Integration and Innovation: The Ecological Trend of Sports Industry under the Background of "Internet+". Journal of Nanjing Sport Institute (Social Sciences), 30, 68-72.

[4] Liu, Y.Y. (2017) Analysis and Construction of Sports Industry Ecology under the Background of "Internet+". Journal of Nanjing Sport Institute (Social Science Edition), 31, 34-39.

[5] Li, D.P., Liang, X.J. and Deng, C.L. (2017) Research on the Development Trend, Driving Force and Innovation Path of Leisure Sports Industry in the Background of "Internet+". Journal of Guangzhou Sports University, 37, 33-36.

[6] Yu, S.W. and Jin, X.Y. (2006) Research on Industrial Integration and Industrial Development of Sports Industry. Sports Science, 26, 16-19.

[7] Yang, Q. (2013) Research on the Internal Mechanism and External Motivation of the Integration and Development of Sports Industry and Related Industries. Journal of Beijing Sports University, 11, 20-24.

[8] He, K. (2016) The Rise and Development Strategy of "Internet+ Sports" Industry. Sports Culture Guide, 5, 130-133.

[9] Zhang, S.M. (2016) Research on the Development Strategy of Internet+ Sports Industry. Sports Culture Guide, 3, 121-124.

[10] Li, H. (2016) Internet Restructuring Sports Industry and Its Future Trend. Journal of Shanghai Institute of Physical Education, 40, 8-15.

[11] Yang, Q. (2015) Research on the Path Mechanism and Reconstruction Model of the Integration Development of Sports and Related Industries. Sports Science, 7, 3-9.

[12] Zhao, A. (2017) Challenges and Optimization Countermeasures of Sports Industry Operation Mode in Internet Era. Journal of Heihe University, 8, 46-47. 